\title{
CURRENT TRENDS IN THE TRAINING OF ELITE JUDO ATHLETES
}

\author{
Laurențiu BOCIOACA $\breve{1}^{1 *}$, Aurel MARIN ${ }^{1}$ \\ ${ }^{1}$ National University of Physical Education and Sport, Faculty of Physical Education and Sport, Bucharest, \\ Romania \\ *Corresponding author: laurbocioaca@yahoo.com
}

https://doi.org/10.35189/dpeskj.2021.60.3.5

\begin{abstract}
Studies on the training of elite judo athletes during the COVID-19 pandemic are indispensable, in the context of observing the necessary measures and their influence on the training components to solve the specific demands of competitive activity. Similar research is being conducted in various countries to determine the impact of the pandemic on the training of judo athletes. This research aims to identify the most efficient means and methods of training and assessment in order to remodel them. The focus is on establishing the main adaptation criteria regarding the way of conducting judo competitions in pandemic conditions, as well as the structure of the fight and its effects on technical, tactical, psychomotor and physical training. Results are statistically processed, interpreted in relation to similar studies and graphically represented. Research participants are elite judo athletes of both genders from different sports clubs, competing in the 2020-2021 Romanian National Judo Championship. The data highlight the characteristics of the fight structure, the actual combat time related to weight divisions, the efficiency of various techniques and the technical and tactical model, the penalties and the relationship with physical training. Determining the effects induced by the new pandemic conditions and training remodelling allow coaches, athletes and methodologists to effectively intervene on the use of material resources, means and methods of training and participation in competition. Conclusions are drawn regarding the characteristics of current competitions and the cause-effect relationship with the selection and training of elite judo athletes in the pandemic context of sports activity.
\end{abstract}

Keywords: judo, training, competition, adaptation.

\section{Introduction}

Judo is a sport characterised by the obligation to use grips in the execution of techniques. Correct grips allow the athlete to perform attack and defence with maximum efficiency through the system of levers achieved and the biomechanics of execution. Judo success is conditioned by high-intensity short bouts, a high level of strength-speed, coordination and endurance in alternating phases of symmetrical and plyometric muscle contractions (Franchini et al., 2018). Victory in judo and combat sports in general is determined by the correct technical and tactical modelling or technical excellence but also by the adaptation to specific demands (Farzad et al., 2011). The importance of judo and combat sports in the economy of Olympic medals is demonstrated by their percentage, namely $26 \%$ of the total number of medals.

The emergence of the need to adapt training and participation in judo competitions, as an effect of the fight against COVID-19, forced coaches, athletes and methodologists to find solutions and means to prevent infection. Social distancing and the lack of direct contact between athletes had an impact on the technical structures of this sport, leading to changes in exercise intensity, changes in equipment due to the obligation of wearing masks but also adaptive changes in programming and planning exercise volume and intensity. 
Numerous authors highlight the importance of technical training in relation to specific physiological demands (Artioli et al., 2012). In other words, a technical athlete is efficient in energy consumption and able to adapt to different combat situations (Beneke et al., 2002).

During training and participation in competitions, the athlete adapts to a certain fighting style and a certain structure of attack and defence techniques, which decisively contributes to physiological adaptation with the development of body mass and exercise capacity specific to the adopted and customised fighting system (Fisher et al., 2011).

Athletes trained according to technical and tactical models specific to the competitive system in which they perform are characterised by the execution of combative techniques and actions requiring a high level of strength, endurance or coordination. Specific adaptation to combat situations and the formation of action blocks in attack and defence produces neuromuscular adaptation with significant increases in strength-speed and muscle power (Franchini et al., 2019), while the formation of a specific defence system develops endurance (Franchini et al., 2016).

The permanent remodelling of the training and participation in competitions leads to changes in approaching the athlete's adaptability. Exercise parameters and their development trends are essential and represent an important step that is taken into account when designing an annual, semestrial, weekly or daily training plan but also for guiding the training methodology and strategy of national federations in the near future (Kamandulis et al., 2018).

Given the particular importance of this issue in the training of any athlete and the fact that the preparation of an annual training plan is the responsibility of coaches, they should have as much information as possible on this topic.

Our reason for choosing this theme is that we considered it appropriate to find the best methods and means of developing annual training plans in which the exercise parameters and dynamics are consistent with the athletes' level of training and potential in the new conditions of the COVID-19 fight. Practice has shown that when the patterns of a scientifically correct training plan and the characteristics of demands and recovery are respected, the results do not fail to show. Therefore, the correct exercise parameters are those that help the athlete to reach an optimal functional state.

\section{Research purpose}

The purpose of this paper is to identify changes in the current training of judo athletes and how exercise capacity and specific structure of the demands is affected in the new conditions. Therefore, this study aims to bring more information on the field of competitive judo by deepening the observations regarding the dynamics of exercise parameters.

\section{Research hypothesis}

The research hypothesis is based on the idea that changes imposed by social distancing and the wearing of masks during training and participation in judo competitions leads to significant changes in the structure of the fight and the preparation for specific exercise. 


\section{Methodology}

The research was conducted between November 2020 and May 2021, and the participants were judo athletes from the UNEFS Sports Club.

The study is based on the analysis of both video recordings from 50 matches and technical data on the organisation of training and competitions in national judo championships. Information provided by coaches of Olympic teams of the Romanian Judo Federation was also used. The data obtained from the analysis of this information were tabulated, statistically processed and graphically represented in order to determine the possibility of optimising the relationship between the technical and tactical training of judo athletes and to compare these data with those recorded for the participants in our research.

The organisation and classification of technical and tactical elements based on the research data used the international algorithmic system, which was due to both the complexity of specific motor actions (attack, counterattack) and changes in the technical structure of the fight with a view to comply with anti-COVID-19 measures.

In the study, the technical procedures performed by the two athletes during the competition are considered offensive combat actions, provided that the technical execution ends with a throwing technique. To determine the appropriate share of technical efficiency and tactical actions performed by the two athletes, we used the ratio between the total number of actions and the attack actions on the right side and the left side but also the actions that were actually scored. All technical actions from the 50 recordings were statistically processed by calculating the arithmetic mean (X) and standard deviation (SD) of the data obtained for the two types of actions consistent with the classification of the techniques. The data were statistically processed and graphically represented to determine the structure and dynamics of the technical model.

Research participants and their specific data are shown in Tables 1 to 4.

Garmin smartwatches were used to record the following physiological indicators: maximal oxygen consumption $\left(\mathrm{VO}_{2} \max \right)$, heart rate $(\mathrm{HR})$ and respiratory rate $(\mathrm{RR})$ during exercise performed with variable intensity and volume. The devices allow storing the activity history and downloading the data to the PC in order to be processed subsequently. During training, the experimental group wore compatible Garmin smartwatches and thus the athletes' performance was analysed in real time to establish the physiological impact of the activity and the efforts provided in order to carry out that activity. This was possible by understanding how the various intensities and changes in intensity supported and triggered the adaptive behaviours of athletes' bodies. Recording the aforementioned physiological indicators allows determining low stress levels or overstress cycles, thus reducing deviation from the optimisation of volume and intensity values. It is found that athletes with a high level of execution of technical and tactical actions are characterised by very good values of physiological indicators, which strengthens the statements according to which specific physical preparation is the result of optimal preparation and modelling of technical and tactical training.

Stress cycles consisting of a 30-second exercise with attack actions and a 30-second break were established as moments specific to exercise-recovery blocks in judo (Farzad et al. 2011). Combat-specific training, especially combat simulation, is characterised by intermittent attack actions, but more and more researchers have started focusing on the effects of complementary high-intensity interval training combined with standard combat training involving specific 
physiological adaptations. Therefore, understanding physiological adaptations and the advantages obtained from intensity modelling can bring valuable information to improve both training programmes and the performance of these athletes.

\section{Results}

Research data on the experimental group include indicators of height, weight and heart rate recorded after the four 30-second bouts with a 30-second active break, as well as maximal oxygen consumption (VO2 max) that was accurately measured with the Garmin device.

Intelligent analyses, which are able to recognise the correct data, ensure the use of only the most important parts of the athletes' performance in order to assess their exercise capacity. High-intensity training that uses 30 -second bouts followed by a 30 -second break, which is characteristic of power demands based on the 1:1 ratio, allows addressing maximal aerobic power and maximal neuromuscular activation highlighted by the values of maximal oxygen consumption (VO2 max).

Systematic or uncontrolled changes in exercise intensity and volume during recordings allow storing the training history and performing its subsequent analysis. The recordings of maximal oxygen consumption were made in the initial phase, at the beginning of the training, and in the final phase, at the end of the training period.

The average values recorded for all indicators were tabulated and statistically processed by calculating the statistical indicators, standard deviation and Student's (Significance) t-Test. Physiological indicators were recorded while athletes performed their favourite techniques during four 30-second bouts followed by a 30-second active break, this length of time being considered the most representative for the average duration of men's combat ( 2 minutes).

Table 1 and Table 2 show the data recorded during the research for the following physiological indicators: maximal oxygen consumption $\left(\mathrm{VO}_{2} \max \right)$, heart rate $(\mathrm{HR})$ and respiratory rate $(\mathrm{RR})$ during exercise. The average values recorded in the initial and final tests were calculated with the help of the Garmin device.

Table 1. Data on somatic and physiological indicators recorded for the experimental group

\begin{tabular}{lcccccc}
\hline Initials & $\begin{array}{c}\text { Height } \\
(\mathrm{cm})\end{array}$ & $\begin{array}{c}\text { Weight } \\
(\mathrm{kg})\end{array}$ & $\begin{array}{c}\mathrm{HR} \\
\text { (beats per minute, } \\
\text { 30ex ercise/30- } \\
\text { sec break) }\end{array}$ & $\begin{array}{c}\text { RR } \\
\text { (breaths per } \\
\text { minute after } \\
\text { exercise) }\end{array}$ & $\begin{array}{c}\mathrm{VO}_{2} \text { max } \\
\text { (initial indirect } \\
\text { determination) }\end{array}$ & $\begin{array}{c}\mathrm{VO}_{2} \text { max } \\
\text { (final indirect } \\
\text { determination) }\end{array}$ \\
\hline S. N. & 162 & 60 & 161 & 48 & 49.84 & 53.14 \\
P. I. & 163 & 48 & 170 & 50 & 49.67 & 53.11 \\
P.A. & 165 & 46 & 168 & 66 & 49.8 & 53.13 \\
S. M. & 173 & 66 & 181 & 70 & 49.12 & 53.21 \\
A.B. & 175 & 73 & 188 & 68 & 48.54 & 53.14 \\
A.S. & 173 & 74 & 200 & 69 & 49.78 & 53.18 \\
N.B. & 177 & 80 & 180 & 60 & 49.16 & 53.24 \\
G. D. & 165 & 62 & 161 & 57 & 49.21 & 53.17 \\
T.V. & 170 & 75 & 170 & 59 & 48.44 & 53.28 \\
V.A. & 183 & 90 & 168 & 63 & 48.76 & 53.44 \\
I.V. & 168 & 76 & 181 & 60 & 48.89 & 52.18 \\
C.A. & 170 & 79 & 188 & 70 & 49.53 & 53.23 \\
P.C. & 169 & 65 & 200 & 74 & 49.78 & 53.31 \\
\hline
\end{tabular}




\begin{tabular}{lllllll}
\hline O.I. & 175 & 80 & 167 & 48 & 49.6 & 52.17 \\
I.V. & 173 & 84 & 180 & 50 & 49.55 & 53.19 \\
M.A. & 180 & 86 & 178 & 66 & 49.51 & 53.15 \\
P.A. & 175 & 81 & 180 & 70 & 49.66 & 53.23 \\
H.Ş. & 177 & 75 & 180 & 68 & 49.23 & 52.54 \\
V.A. & 166 & 39 & 174 & 69 & 49.22 & 53.13 \\
B.A. & 169 & 63 & 165 & 60 & 49.8 & 53.14 \\
\hline
\end{tabular}

Table 2. Statistical data on somatic and physiological indicators recorded for the experimental group

\begin{tabular}{lcccc}
\hline Mean $(\mathrm{X})$ & 177 & 62.25 & 49.3545 & 53.0655 \\
SD & 3.19 & 4.08 & 2.23 & 2.58 \\
$\mathrm{t}-$ Test & 2.08 & 2.03 & & \\
\hline
\end{tabular}

Statistical processing of the results indicates significant changes in the maximal oxygen consumption $\left(\mathrm{VO}_{2}\right.$ max), which is demonstrated by the values obtained for Student's t-Test (2.08 and 2.03, respectively) at a threshold with the p-value $=001$. These data confirm the assumption that training that uses 30 -second bouts with athletes wearing masks leads to a significant increase in oxygen consumption from the very beginning of the fight, which is also supported by the findings of similar studies (Franchini et al., 2016).

Table 3. Data specific to the technical execution structure during ground fighting with contact restriction

\begin{tabular}{lcccc}
\hline $\begin{array}{c}\text { Name of the techniques } \\
\text { performed according to } \\
\text { international classifications }\end{array}$ & $\begin{array}{c}\text { Total number } \\
\text { of attack } \\
\text { actions }\end{array}$ & $\begin{array}{c}\text { Number of } \\
\text { attack actions } \\
\text { on the left side }\end{array}$ & $\begin{array}{c}\text { Number of } \\
\text { attack actions on } \\
\text { the right side }\end{array}$ & $\begin{array}{c}\text { Number of } \\
\text { actually } \\
\text { scored actions }\end{array}$ \\
\hline SEOI-NAGE & 216 & 129 & 87 & 20 \\
UCHI- MATA & 170 & 102 & 68 & 16 \\
TAI-OTOSHI & 40 & 22 & 18 & 3.7 \\
O-UCHI-GARI & 74 & 44 & 30 & 7 \\
KO-UCHI-GARI & 48 & 37 & 11 & 4.4 \\
HARAI-GOSHI & 47 & 25 & 22 & 4 \\
O-SOTO-GARI & 32 & 18 & 14 & 3 \\
KO-SOTO-GARI & 30 & 17 & 13 & 2.77 \\
YOKO-OTOSHI & 21 & 12 & 9 & 2 \\
SEOI-OTOSHI & 26 & 14 & 12 & 2.4 \\
TANI-OTOSHI & 23 & 13 & 10 & 2.1 \\
KATA-GURUMA & 31 & 17 & 14 & 2.87 \\
DE-ASHI-HARAI & 32 & 17 & 15 & 3 \\
SASAE-TSURI & 8 & 3 & 5 & 0.74 \\
MOROTE-GARI & 30 & 16 & 14 & 2.77 \\
TOMOE-NAGE & 43 & 25 & 18 & 4 \\
SUMI-GAESHI & 35 & 15 & 20 & 3.24 \\
O-GOSHI & 41 & 24 & 17 & 2.87 \\
URA-NAGE & 14 & 10 & 4 & 2 \\
SUMI-OTOSHI & 20 & 5 & 15 & 2 \\
USHIRO-GOSHI & 30 & 17 & 13 & 2.77 \\
SODE-TSURI-KOMI-GOSHI & 25 & 15 & 10 & 2.31 \\
OTHER & 26 & 16 & 10 & 2.4 \\
\hline
\end{tabular}


Table 3 indicates that there is reorganisation of both the types of techniques performed and the attack actions on the two directions (left and right) but also intensification of technical executions with minimum and maximum speed risk besides foot and leg techniques.

Athletes believe that sweeping and reaping techniques, which require a high level of development of motor skills (speed, strength and coordination) as well as fast grips are the most efficient, which is also highlighted by other researchers (Monks et al., 2017). Shoulder turnover techniques are equally significant in the structure of the fight.

Table 4. Statistical indicators specific to the structure of technical and tactical actions performed under conditions of minimum contact with the opponent during the standing fight

\begin{tabular}{lcccc}
\hline TOTAL & 1062 & 613 & 449 & 98.34 \\
\hline Mean & 88.5 & 51.08 & 37.41 & 8.19 \\
SD & 5.92 & & & \\
t-Test & 0.04 & & & \\
\hline
\end{tabular}

Calculation of the statistical indicators of technical and tactical actions (Table 4) reveals a significant increase in attacks on the left side performed by the whole experimental group and but also in the number of attack actions recorded during the 50 matched analysed for the current study, which demonstrates a reorientation of the technical model towards fighting with grips on the left side to surprise the opponent and reduce the contact with them.

The significant value of direct attacks on the left side is supported by the data recorded for Student's t-Test (0.04) at a threshold with the p-value $=001$. There is also a significant variability in the techniques used, which is emphasised by the value of the standard deviation, namely 5.92. This demonstrates the adaptation of athletes to different execution techniques, their increased creativity during the fight and the fact that the time needed for them to perform and prepare combat actions has shortened (Murărețu \& Teodoru, 2014) even if restrictions regarding contact and grips tend to narrow the field of action. The techniques with the highest level of execution are performed by most participants in this study, for example foot and leg sweeping and reaping techniques that require a high level of development of motor skills (speed, strength and coordination) as well as grips performed quickly and involving low complexity in execution. 


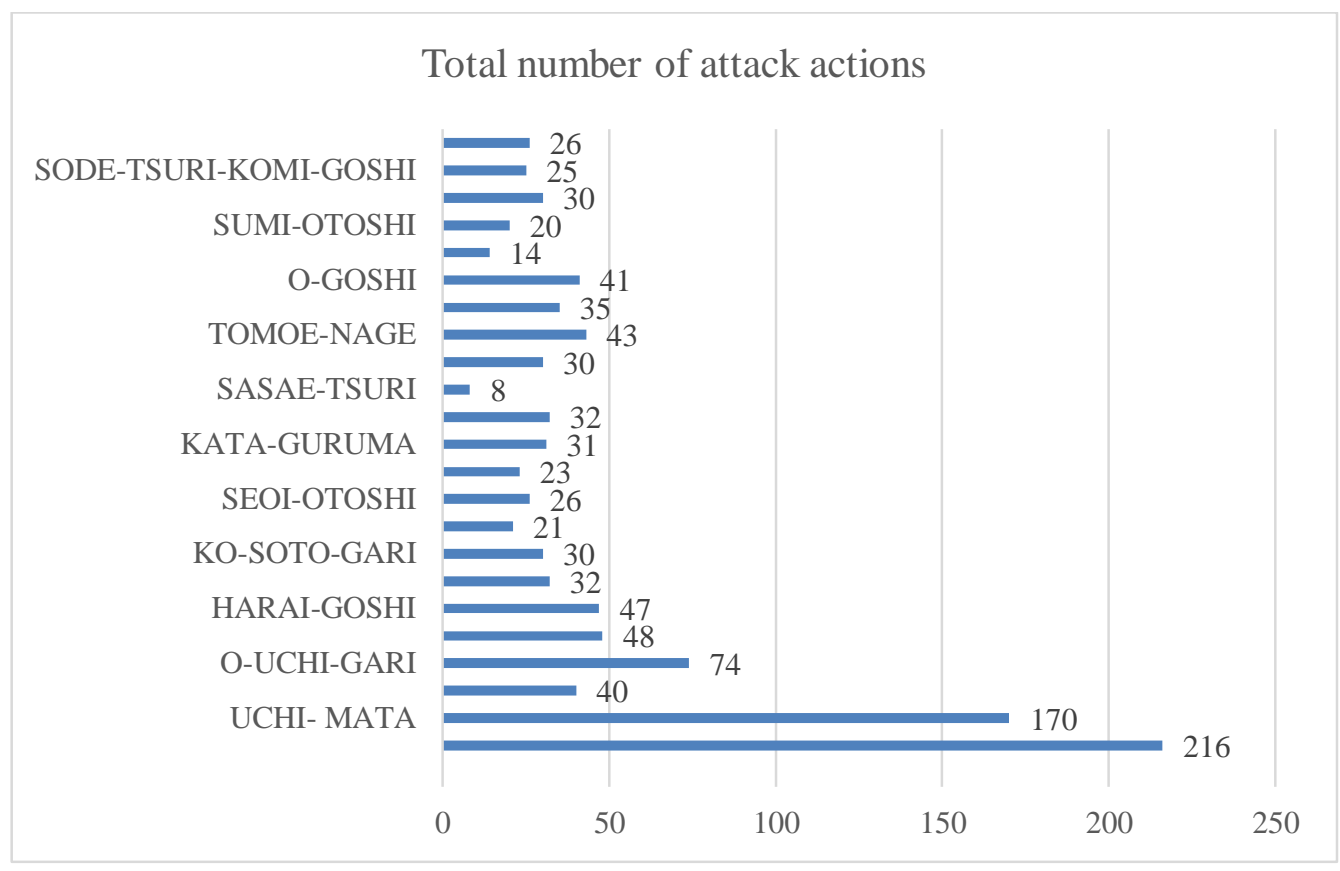

Figure 1. Total number of attack actions performed for different techniques

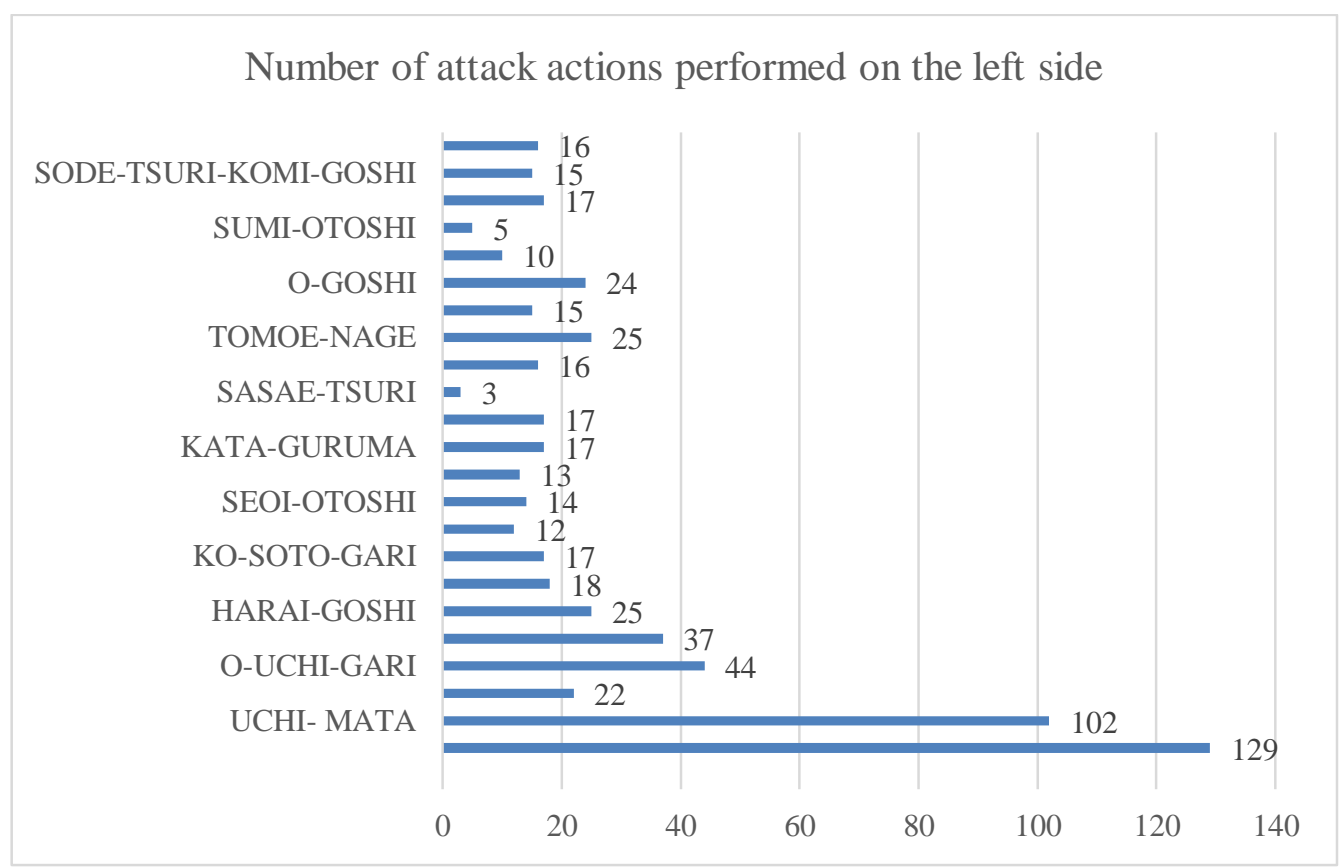

Figure 2. Number of attack actions performed on the left side

The structure of actions performed on the left side (Figure 2) indicates very high correlations compared to the overall structure of actions, which demonstrates the existence of an adaptive rather than random structure, a model argued by the values of the Significance t-Test. This is the result of the systematic training of athletes in an organised setting, which leads to responses correlated with judo-specific demands. 


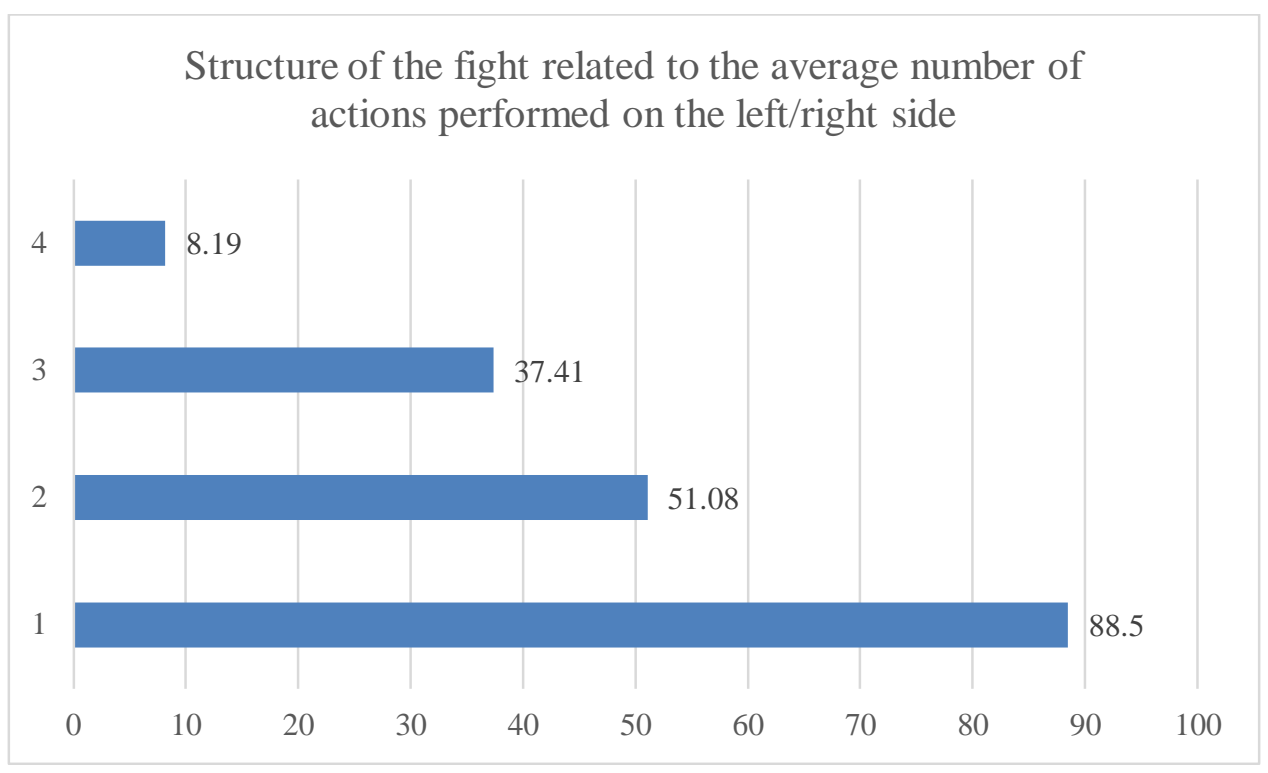

Figure 3. Structure of the fight related to the average number of actions performed on the left/ right side

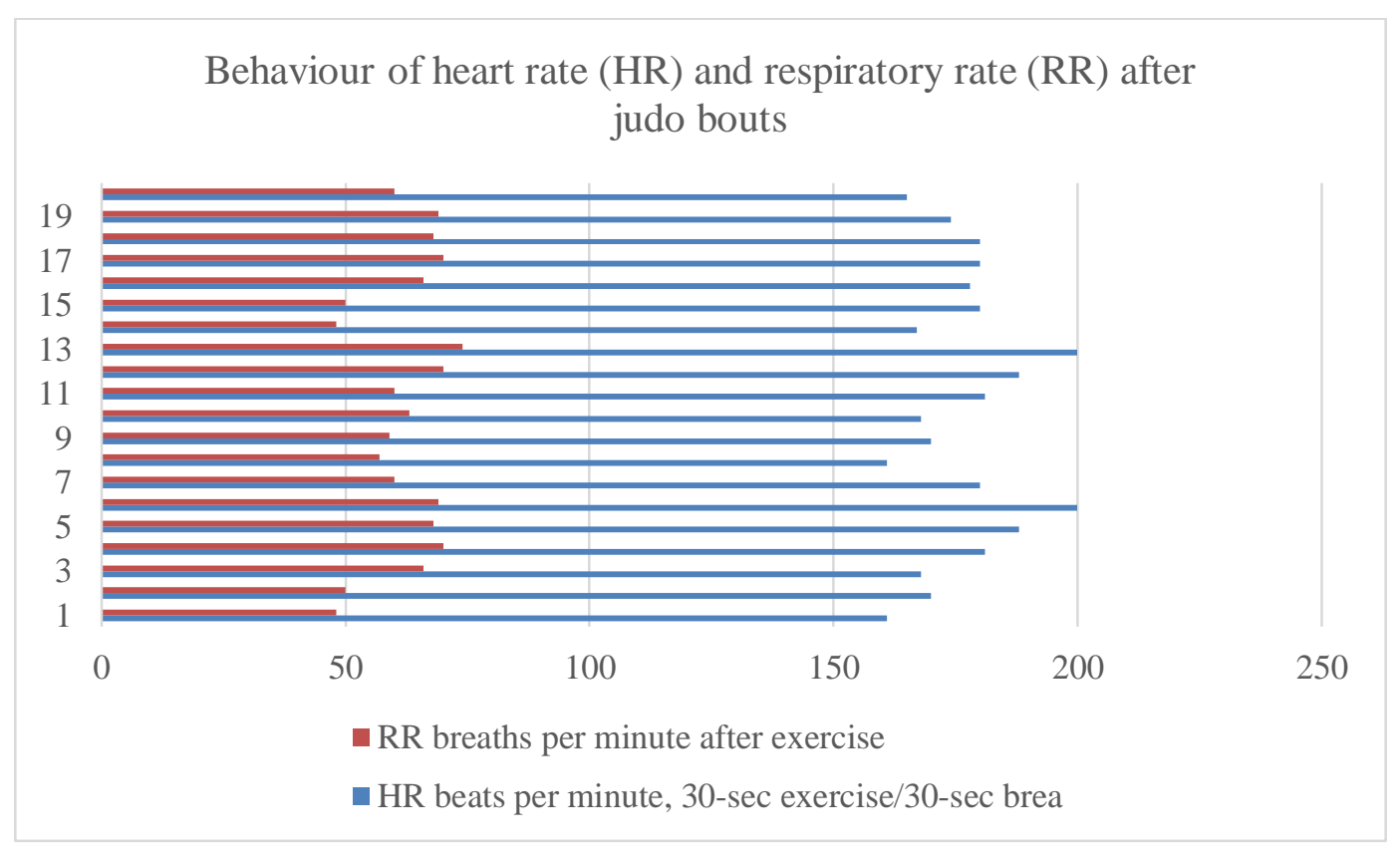

Figure 4. Behaviour of heart rate (HR) and respiratory rate (RR) after judo bouts

\section{Conclusion}

The specific conditions for conducting this research during the anti-COVID fight highlight the importance of changes in the preparation and development of the competitive fight. The recorded data demonstrate the importance of wearing masks and changing specific demands for judo athletes but also for all athletes practicing various martial arts. Wearing masks during training sessions and limiting contact with the opponent through the attack and defence actions carried out leads not only to changes in the physiological demand and significant increases in 
oxygen consumption but also to changes in the technical and tactical structure of the fight (Ravier et al., 2009).

Significant increases in maximal oxygen consumption $\left(\mathrm{VO}_{2} \max \right)$ cause the training and competitive activity to be performed with short bouts of 1 to 2 minutes, and the techniques predominantly performed on one side allow avoiding grip changes and carrying out attack actions with minimal risk. There are also increases in the values of physiological indicators for all investigated athletes, which confirms the hypothesis, the values recorded for Student's tTest being 0.04 at a threshold with the p-value $=001$ and a standard deviation of very high variability, namely 5.92. The data obtained from our research demonstrate the significant adaptation of each athlete to judo-specific demands. It has been noted that heart rate (HR) and respiratory rate $(\mathrm{RR})$ record significant increases simultaneously with the increase in exercise intensity, which is also amplified by the need for oxygen under the conditions of oxygen debt accumulation due to the obligation for athletes to wear masks.

The weight of anaerobic exercise as well as strength-speed and power actions specific to the standing technique increases significantly (Sale et al., 1990). Eliminating the techniques used during ground fighting and exclusively using the standing technique amplifies the importance of strength and simple grip techniques, which are specific to direct attack actions on the surprise side. In these conditions, the specific means of training impose the orientation towards individualised training performed without a partner but with auxiliary means (for example Tandoku-Renshu or Solo Judo Exercises), which is imperative to become a priority throughout the preparation period when maximum avoidance of contact and keeping the fighting distance are required.

The structure of actions performed on the left side indicates very high correlations compared to the overall structure of actions, which demonstrates the existence of an adaptive rather than random structure, a model argued by the values of the Significance t-Test. This is the result of the systematic training of athletes in an organised setting, which leads to responses correlated with judo-specific demands.

Specific training is thus oriented towards lower efforts in terms of volume and intensity, with short bouts of 1 to 2 minutes, and the use of plyometric exercises that are predominant in the training structure. Significant increases in heart rate (HR) and respiratory rate (RR) for the whole group of investigated athletes are accompanied by significant increases in oxygen debt, which is highlighted by the significantly increased values of maximal oxygen consumption $\left(\mathrm{VO}_{2} \max \right)$ recorded at the end of the bouts, when the athlete's body tries to recover the oxygen debt (Turner et al., 2014).

High-intensity training has generally led to increases in $\mathrm{VO}_{2}$ max ranging from $4.4 \%$ to $23.0 \%$ in judo athletes. This finding reinforces the statement made by Ravier et al. (2009) that aerobic exercise contributes to the faster recovery of athletes practising judo and martial arts, their results suggesting that high-intensity interval training can help enhance athletes' recovery between successive high-intensity actions or between competitions. Moreover, the most important advantage of training with short blocks of intensity ranging between 30 seconds and 1 minute produces an increase in anaerobic capacity and leads to the recovery of oxygen debt within a short time, which decisively contributes to obtaining the score during the fight.

There is also a significant variability in the techniques used, which is emphasised by the value of the standard deviation, namely 5.92. This demonstrates the adaptation of athletes to 
different execution techniques, their increased creativity during the fight and the fact that the time needed for them to perform and prepare combat actions has shortened even if restrictions regarding contact and grips tend to narrow the field of action.

The techniques with the highest level of execution are performed by most participants in this study, for example foot and leg sweeping and reaping techniques that require a high level of development of motor skills (speed, strength and coordination) as well as grips performed quickly and involving low complexity in execution.

All these data lead us to continue the research in order to determine the adaptive changes of judo athletes in the post-COVID period and to establish the directions for implementing the data in the new training structure. Training modelling by integrating specific demands is a necessity that coaches and athletes are entitled to adopt as a maximum efficiency strategy.

\section{References}

Artioli, G. G., Bertuzzi, R. C., Roschel, H., Mendes, S. H., Lancha Jr., A. H., \& Franchini, E. (2012). Determining the contribution of the energy systems during exercise. Journal of Visualized Experiments, 61: 3413. https://doi.org/10.3791/3413

Beneke, R., Pollmann, C., Bleif, I., Leithäuser, R., \& Hütler, M. (2002). How anaerobic is the Wingate Anaerobic Test for humans? European Journal of Applied Physiology, 87, 388392. https://doi.org/10.1007/s00421-002-0622-4

Farzad, B., Gharakhanlou, R., Agha-Alinejad, H., Curby, D. G., Bayati, M., Bahraminejad, M., \& Mäestu, J. (2011). Physiological and performance changes from the addition of a sprint interval program to wrestling training. The Journal of Strength and Conditioning Research, 25(9), 2392-2399. https://doi.org/10.1519/jsc.0b013e3181fb4a33

Fisher, G., Schwartz, D. D., Quindry, J., Barberio, M. D., Foster, E. B., Jones, K. W., \& Pascoe, D. D. (2011). Lymphocyte enzymatic antioxidant responses to oxidative stress following high-intensity interval exercise. Journal of Applied Physiology, 110(3), 730-737. https://doi.org/10.1152/japplphysiol.00575.2010

Franchini, E., Cormack, S., \& Yuri Takito, M. (2019). Effects of high-intensity interval training on Olympic combat sports athletes' performance and physiological adaptation: A systematic review. The Journal of Strength and Conditioning Research, 33(1), 242-252.

https://doi.org/10.1519/jsc.0000000000002957

Franchini, E., Schwartz, J., \& Yuri Takito, M. (2018). Maximal isometric handgrip strength: Comparison between weight categories and classificatory table for adult judo athletes. Journal of Exercise Rehabilitation, 14(6), 968-973. http://dx.doi.org/10.12965/jer.1836396.198

Franchini, E., Julio, U. F., Panissa, V. L. G., Lira, F. S., Gerosa-Neto, J., \& Branco, B. H. M. (2016). High-intensity intermittent training positively affects aerobic and anaerobic performance in judo athletes independently of exercise mode. Frontiers in Physiology, 7: 268. https://doi.org/10.3389/fphys.2016.00268

Kamandulis, S., Bruzas, V., Mockus, P., Stasiulis, A., Snieckus, A., \& Venckunas, T. (2018). Sport-specific repeated sprint training improves punching ability and upper-body aerobic power in experienced amateur boxers. The Journal of Strength and Conditioning Research, 32(5), 1214-1221. https://doi.org/10.1519/JSC.0000000000002056

Monks, L., Seo, M.-W., Kim, H.-B., Jung, H. C., \& Song, J. K. (2017). High-intensity interval training and athletic performance in Taekwondo athletes. The Journal of Sports Medicine and Physical Fitness, 57(10), 1252-1260. https://doi.org/10.23736/S0022-4707.17.06853-0 
Murărețu, C., \& Teodoru, M. (2014). Concentration time in 53 kg Women's Weightlifting, Clean and Jerk style. Procedia - Social and Behavioral Sciences, 117, 352-356. https://doi.org/10.1016/j.sbspro.2014.02.226

Ravier, G., Dugué, B., Grappe, F., \& Rouillon, J. D. (2009). Impressive anaerobic adaptations in elite karate athletes due to few intensive intermittent sessions added to regular karate training. Scandinavian Journal of Medicine \& Science in Sports, 19(5), 687-694. https://doi.org/10.1111/j.1600-0838.2008.00807

Sale, D. G., McDougall, J. D., Jacobs, I., \& Garner, S. (1990). Interaction between concurrent strength and endurance training. Journal of Applied Physiology, 68(1), 260-270. https://doi.org/10.1152/jappl.1990.68.1.260

Turner, A., James, N., Dimitriou, L., Greenhalgh, A., Moody, J., Fulcher, D., Mias, E., \& Kilduff, L. (2014). Determinants of Olympic fencing performance and implications for strength and conditioning training. The Journal of Strength and Conditioning Research, 28(10), 3001-3011. https://doi.org/10.1519/jsc.0000000000000478 